\title{
Response Surface Modeling of Fuel Rich and Fuel Lean Catalytic Combustion of the Stabilized Confined Turbulent Gaseous Diffusion Flames
}

\author{
Tahani S. Gendy, Salwa A. Ghoneim*, Amal S. Zakhary \\ Egyptian Petroleum Research Institute (EPRI), Cairo, Egypt \\ Email: *salwaghoneim70@yahoo.com
}

How to cite this paper: Gendy, T.S., Ghoneim, S.A. and Zakhary, A.S. (2019) Response Surface Modeling of Fuel Rich and Fuel Lean Catalytic Combustion of the Stabilized Confined Turbulent Gaseous Diffusion Flames. World Journal of Engineering and Technology, 7, 1-17. https://doi.org/10.4236/wjet.2019.71001

Received: November 14, 2018

Accepted: December 17, 2018

Published: December 20, 2018

Copyright ( $) 2019$ by authors and Scientific Research Publishing Inc. This work is licensed under the Creative Commons Attribution International License (CC BY 4.0).

http://creativecommons.org/licenses/by/4.0/

\section{c) (i) Open Access}

\begin{abstract}
The Response Surface Methodology (RSM) has been applied to explore the thermal structure of the experimentally studied catalytic combustion of stabilized confined turbulent gaseous diffusion flames. The Pt $/ \gamma \mathrm{Al}_{2} \mathrm{O}_{3}$ and $\mathrm{Pd} / \gamma \mathrm{Al}_{2} \mathrm{O}_{3}$ disc burners were situated in the combustion domain and the experiments were performed under both fuel-rich and fuel-lean conditions at a modified equivalence (fuel/air) ratio (Ø) of 0.75 and 0.25 respectively. The thermal structure of these catalytic flames developed over the Pt and Pd disc burners were inspected via measuring the mean temperature profiles in the radial direction at different discrete axial locations along the flames. The RSM considers the effect of the two operating parameters explicitly $(r)$, the radial distance from the center line of the flame, and $(x)$, axial distance along the flame over the disc, on the measured temperature of the flames and finds the predicted maximum temperature and the corresponding process variables. Also the RSM has been employed to elucidate such effects in the three and two dimensions and displays the location of the predicted maximum temperature.
\end{abstract}

\section{Keywords}

Catalytic Combustion, Fuel Lean/Fuel Rich, Noble Metals Burners, Thermal Structure, Modeling, Response Surface Method

\section{Introduction}

Catalytic combustion of various hydrocarbon fuels over noble metals addresses the interaction between homogeneous and heterogeneous reactions and it is par- 
ticularly attractive for the latest power generation technologies aiming at mitigating greenhouse $\mathrm{CO}_{2}$ emissions [1]. Catalytic combustion methodologies are increasingly explored in the last years due to their enhanced combustion stability at very fuel-lean equivalence ratios and the resulting ultra-low NOx emissions [2] [3]. Catalytic-rich combustion is of interest not only for natural gas but also for hydrogen and syngas fuels. In this case the catalyst does not only have a prime catalytic partial oxidation function, but also acts as a preheater and stabilizer for subsequent homogeneous combustion zone [4] [5]. Progress in catalytic combustion depends crucially on advances in catalyst technology and in multi-dimensional modeling for reactor design [6].

Recently the catalytic combustion has been dealt with numerically. Lucci et al. [6] investigated the turbulent catalytic combustion of a fuel-lean hydrogen/air mixture by means of three-dimensional direct numerical simulation (DNS) in a platinum-coated plane channel. Schultze et al. [7] investigated experimentally and numerically employing two-dimensional model the hetero/homogeneous combustion of hydrogen/air mixture over Pt at stochiometries: $2.0 \leq \varnothing \leq 7.0$ at 1.0 bar $\leq \mathrm{p} \leq 5$ bar. Moreover Schultze \& Mantzaras [3] employed two-dimensional numerical simulations models to deal with the physicochemical processes during the fuel-lean and fuel rich catalytic combustion of hydrogen/air mixtures in platinum-coated channels. Zheng et al. [2] investigated experimentally and numerically the homogeneous combustion of fuel-lean syngas mixtures over platinum at elevated pressures and preheats. Yan et al. [8] studied the numerical of effect of wall parameters on catalytic combustion characteristics of $\mathrm{CH}_{4} /$ air in a heat recirculation micro-combustor made of different materials. Arani et al. [1] carried out three-dimensional direct numerical simulations (DNS) with detailed heterogeneous and homogeneous chemistry and transport to investigate the turbulent combustion of fuel-lean hydrogen/air mixtures in a platinum-coated channel with prescribed wall temperatures.

The present study analyzes mathematically through Response Surface Modeling (RSM) and optimization the previously reported experimental data of thermal structure of catalytic stabilized confined turbulent gaseous diffusion flames over $\mathrm{Pt} / \gamma \mathrm{Al}_{2} \mathrm{O}_{3}$ and $\mathrm{Pd} / \gamma \mathrm{Al}_{2} \mathrm{O}_{3}$ catalytic disc burners under fuel-rich and fuel-lean conditions [9].

The RSM has been utilized to study the effect of two different operating factors, specifically the radial distance from the center line of the flame $(r)$ and axial distance lengthwise the flame over the disc $(x)$ on the mean radial temperature profiles of the established stabilized flames. Also RSM has been utilized to demonstrate such effects in the three and two dimensions and shows the location of the predicted optimum maximum temperature for the scrutinized catalytic disc burners under fuel-rich and fuel-lean conditions.

\section{Experimental}

Details of the experimental setup and the data investigated in this study have 
been specified the previous work of [9].

\subsection{Response Surface Methodology}

Response surface methodology (RSM) is an assembly of mathematical and statistical technique used for modeling and analyzing a process in which a response of interest is influenced by several variables and the aim is to optimize this response [10] [11] [12] [13]. This technique is one of the major quantitative tools in industrial decision making as it gives better understanding of the process; it helps the process engineer to see the effect of the control variables simultaneously and the interactions among all the variables [10]. It generates a mathematical model; its graphical perspective has led to the term Response Surface Methodology [14]. Graphic drawings of the shape of the surfaces allow a visual explanation of the functional relations between the response and the experimental variables [11] [12]. RSM also permits the location of the optimum conditions and sensitivity analyses of the optimum conditions to variations in the settings of the experimental variables. This technique has many advantages such as: cost and time reduction, decreasing the number of tests and valuable in attaining maximum efficiency [15].

In the last decade, RSM has been extensively utilized for modeling and optimization of several engineering processes and studies as optimization of media, process conditions, catalyzed reaction conditions, oxidation, production, fermentation, biosorption of metals, thermal cracking of petroleum residue oil, water and waste water treatment, membrane systems, electronics, removal of nickel and lead from petroleum waste water chemical systems like distillation and in modeling and optimizing refinery operations [10] [16] [17] [18].

This RSM procedure includes the following steps [19]: 1) definition of independent input variables and the desired output responses, and carrying out the required experiments, 2) performing regression analysis with the quadratic model of RSM, 3) calculate analysis of variance (ANOVA) for the independent input variables in order to find significant parameters that affect the responses, 4) determination of the situation of the quadratic model of Response Surface Methodology and decide whether the model of RSM needs screening variables or not and finally, 5) optimization.

\subsection{Response Surface Models}

Assuming all variables to be to be independent; continuous; measurable and controllable by experiments with negligible errors, the correlation between the response $y$ and independent variables $\xi_{1}, \xi_{2}, \ldots, \xi_{k}$ could be represented by the following equation [20]:

$$
y=f\left(\xi_{1}, \xi_{2}, \ldots, \xi_{k}\right)+\varepsilon
$$

The form of the true response function $f$ is unidentified and perhaps very complex and $\mathcal{E}$ is a term that represents a random experimental error not ac- 
counted for in $f$ assumed to have a zero mean. The variables $\xi_{1}, \xi_{2}, \ldots, \xi_{k}$ in Equation (1) are usually called the natural variables. The units of the natural independent variables vary from one another. Even if some of the parameters have the same units, not all of these parameters will be tested over the same range. Before performing the regression analysis the variables are codified to eliminate the effect of different units and ranges in the experimental domain and allows parameters of different magnitude to be investigated more evenly in a range between -1 and +1 [14] [21] [22].

Below is the frequently used equation for coding:

$$
\text { coded value }=\frac{\text { actual value }- \text { mean }}{\text { half of range }}
$$

Frequently, a low- or second-order polynomial model is proper [11] [12] [20]. The relationship between the coded variables and the response is modeled, in this study, by modifying the experimental data to a second-order polynomial, which is suitable for studying the interaction effects of process parameters on the response, according to the following equation [19]:

$$
Y=\beta_{0}+\sum_{i=1}^{k} \beta_{i} X_{i}+\sum_{i=1}^{k} \beta_{i i} X_{i}^{2}+\sum_{\substack{i=1 \\ i<j}}^{k-1} \sum_{j=2}^{k} \beta_{i j} X_{i} X_{j}+\varepsilon
$$

where, $Y$ is the response variable; $X_{i}$ and $X_{j}$ are the coded input variables that affect the response variable and $\varepsilon$ denotes the random error or uncertainties between predicted and measured values [22]. $k$ is the number of variables, and $\beta_{0}, \beta_{i}, \beta_{i i}$ and $\beta_{i j}$ are the regression constants of intercept, linear, quadratic and interaction terms, respectively [23] [24]. This flexible coded model permits the factor coefficients to become directly analogous to one another, which assists for the scale-free ranking of the relative significance of the factors [25].

In order to estimate the unknown parameters in model (3), a series of experiments have been executed in each of which the response $y$ is measured for identified settings of the control variables that result in a maximum or a minimum response over a certain region of interest [9].

Ordinary Least Squares (OLS) method that diminishes the variance of the balanced estimators of the coefficients has been performed to evaluate the coefficients of the equation. It assumes that the random errors are identically distributed with a zero mean and a common unknown variance and they are independent of each other [14]. Removing unimportant coefficients for terms which did not affect the response, OLS method has been applied for the model without them. The final model contains only substantial parameters (with p-value < 0.05) [26]. To guarantee that the equation fits the data well, the suitability of the "fitted" equations has been assessed through the following indicators [27] [28] [29] [30].

\subsection{Regression Statistics}

Coefficient of determination $R^{2}$ : It is a measure of the ability of the regression equation to estimate the real response data. It also explains the overall predictive 
capability of the model and confirms its goodness of fit [24].

Adjusted $R^{2}$ : It is an unbiased evaluation of the coefficient of determination. It reprimands the statistic $R^{2}$ if redundant variables terms are included in the model.

$F$-value is employed to assess the overall significance of the model. At a specific level of significance ( $\alpha$-value) the calculated value of $F$ should be greater than the corresponding tabulated value [19] [31].

Regression Significance F: A substantial correlation is considered to exist between the independent and dependent variables if this value $<\alpha=0.05$ [18].

$p$-value of each coefficient and the $Y$-intercept less than 0.05 designates that the corresponding variable has a considerable effect on the response with a fitting level of more than $95 \%$. Coefficient with smaller p-value or greater magnitude of $\mid t$-value| signifies more impact into the model equation [15] [32].

Confidence Limits are the $95 \%$ possibility that the real value of the coefficient lies amid the 95\% Lower and Upper values. Thinner range is desirable.

\subsection{Prediction Statistics}

Predictive Error Sum of Squares (PRESS): It evaluates how the equation model predicts each experimental point in the design and how it is likely to forecast the response in a new experiment within the experimental domain. Small values are wanted [30] [33].

Predicted $R$-Squared ( $\boldsymbol{R}_{\text {pred }}^{2}$ ): It is a measure of the extent of deviation in prediction of new data clarified by the model and it is calculated from PRESS. $R_{\text {pred }}^{2}$ and $R_{\text {adj }}^{2}$ should be within 0.20 of each other [14] [30] [33].

Adequate precision statistic (Adeqval) is employed to evaluate the ratio of the signal to noise. A ratio greater than 4 is an indicator of suitable model variation and the model could be used to traverse the design space [19].

Coefficient of Variation ( $C V$ ) designates the degree of accuracy with which experiments were implemented. Values below $10 \%$ might be considered outstanding [10] [34].

Average absolute deviation $(A A D)$ is a sign of the goodness of fit of the equation and a straight method for describing the deviations. The $A A D$ is estimated by the following equation:

$$
A A D=\left\{\left[\sum_{i=1}^{n}\left(\left|y_{i, \exp }-y_{i, c a l}\right| / y_{i, \text { exp }}\right)\right] / n\right\} * 100
$$

where $y_{i, \exp }$ and $y_{i, \text { cal }}$ are the experimental and calculated responses and $\mathrm{n}$ is the number of experimental runs [14] [15].

\subsection{Residuals Analysis}

Graphical residual analysis should be performed to legalize the assumptions involved in the ANOVA of a normal residuals distribution (the normal probability plot vs studentzed residuals will be like a straight line) and homogeneity of the variance (structure less plot of studentized residuals vs. run time or the predicted response) [24] [33] [35]. 


\subsubsection{Application of RSM to the Present Work}

The following formulas have been employed to calculate the coded factors of $(r)$ and $(x)$ :

$$
R=r / 75, X=\frac{x-127.5}{97.5}
$$

where: $r$ radial distance from the center line of the flame $(\mathrm{mm}) ; x$. Axial distance along the flame over the disc $(\mathrm{mm})$.

In the present work the following equation has been applied employing the above formulas (5) for coding the factors:

$$
Y=\beta_{0}+\beta_{1} * R+\beta_{2} * X+\beta_{11} * R^{2}+\beta_{22} * X^{2}+\beta_{12} * R * X
$$

To establish the correlation between dependent response and independent variables numerous mathematical models have been suggested. A suitable power transformation to the response data could be recognized using the Box-Cox method for normalizing the data or equalizing its variance [31] [33].

\subsubsection{Box-Cox Method (BC)}

An appropriate power transformation $\lambda$ for the data is established on the relation $Y^{*}=Y^{\lambda}$.

$\lambda$ is calculated using the experimental given data such that $\mathrm{SS}_{\mathrm{E}}$ is minimized (where $\mathrm{E}$ is the error between the given experimental response values and the analogous transformed ones $Y^{*}$ ). The following relation (7) has been employed to obtain $Y^{\lambda}$ :

$$
Y^{\lambda}= \begin{cases}\frac{Y^{\lambda}-1}{\lambda} \frac{1}{g^{\lambda-1}}, & \text { if } \lambda \neq 0 ; \\ \ln Y \times g, & \text { if } \lambda=0\end{cases}
$$

where: $g$ is the geometric mean of the experimental response vector.

For a number of $\lambda$ values the corresponding $Y^{\lambda}$ and $\mathrm{SS}_{\mathrm{E}}$ is calculated for these values to obtain a plot of $\mathrm{SS}_{\mathrm{E}}$ versus $\lambda$. Because the range of $\mathrm{SS}_{\mathrm{E}}$ values is large, this is performed by plotting the $\ln \left(\mathrm{SS}_{\mathrm{E}}\right)$ versus $\lambda$ values. The $\lambda$ value of corresponding to the minimum $\ln \left(\mathrm{SS}_{\mathrm{E}}\right)$ is selected and its $100(1-\alpha)$ percent confidence interval is calculated. If the interval for $\lambda$ do not include the value of one, then the conversion is applicable for the given response data. For details of this method refer to [33] [36].

This method has been exploited and the results are portrayed in Figures 1(a)-(d) and Table 1. The values of the sqrt ( $T$ ) of the mean experimental temperature $T$ dependent variable cited in [9] have been employed to represent the response $Y$ in Equation (6).

\section{Results and Discussions}

The regression has been accomplished by means of Microsoft Excel 2010 and Matlab 8.1 to estimate the coefficients of Equation (6) for the coded factors along side with the statistical parameters which validate the results. Regression 
Table 1. Values of BOX COX Plot.

\begin{tabular}{ccccc}
\hline \multirow{2}{*}{ BOX COX Plot } & \multicolumn{4}{c}{ Flame Condition and Disc Type } \\
\cline { 2 - 5 } & FR_Pt & FL_Pt & FR_Pd & FL_Pd \\
\hline Risk Level $\alpha$ & 0.05 & 0.05 & 0.05 & 0.05 \\
Best Lambda & 0.6836 & 0.5622 & 0.5412 & 0.6152 \\
$\lambda$ for Low Confidence & 0.4417 & 0.5101 & 0.46354 & 0.52878 \\
$\lambda$ for High Confidence & 0.9754 & 0.6188 & 0.62388 & 0.70727 \\
$\operatorname{Ln}$ (RSSE) for Confidence Interval & 14.373 & 13.273 & 13.494 & 13.493 \\
\hline
\end{tabular}

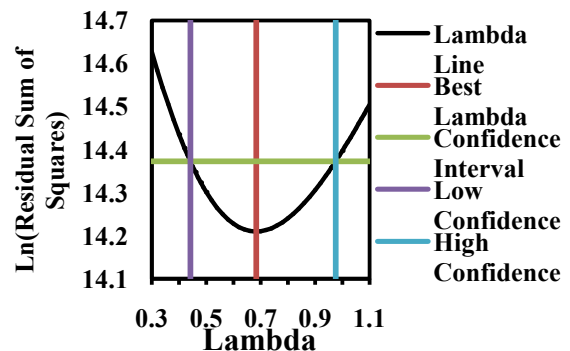

(a)

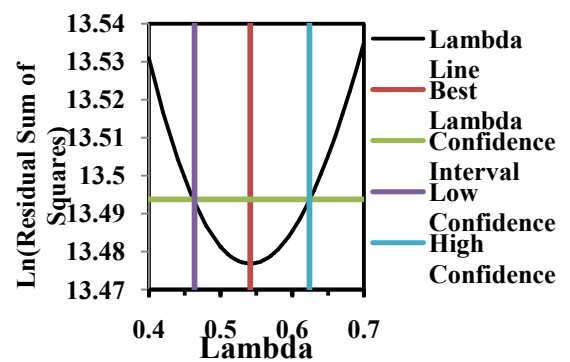

(c)

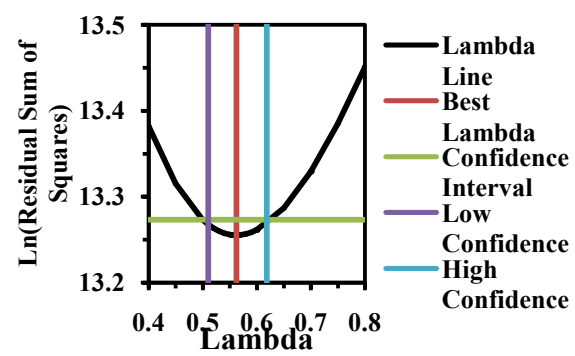

(b)

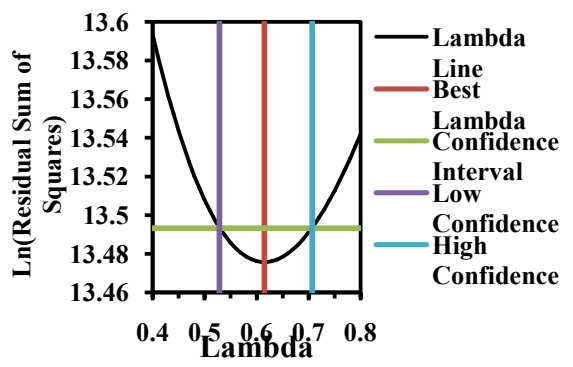

(d)

Figure 1. (a) BOX COX Plot for FR_Pt; (b) BOX COX Plot for FL_Pt; (c) BOX COX Plot for FR_Pd; (d) BOX COX Plot for FL_Pd.

and Prediction Statistics and the Analysis of Variance which checks the significance and fitness of quadratic equation models have been depicted in Table 2 . The very large $F$-values and a very small Significance $\mathrm{F}$ values implies that the equation models are highly significant for all terms in the polynomial equation within $95 \%$ confidence interval and are adequate to predict the responses. The high determination coefficient $\left(R^{2} \geq 0.95\right)$ indicates the accuracy of the deduced models. The high and very close agreement between the " $R_{\text {pred }}^{2}$ " values with the corresponding " $R_{\mathrm{adj}}^{2}$ " ones imply the real and good relation between the independent and dependent variables together with the high degree of correlation between the measured and predicted data from the regression models. The adequate precision values of (106 - 193) show good models discrimination and each of these models could be used to traverse the design space. The low values of PRESS and $C V<10$ display the high accuracy; reliability and good consistency of the accomplished experiments and that the models were reproducible. Finally 
Table 2. Regression and prediction statistics and analysis of variance for the catalyticflame stabilizing disc burners.

\begin{tabular}{|c|c|c|c|c|c|c|}
\hline & \multirow{2}{*}{\multicolumn{2}{|c|}{$\begin{array}{l}\text { ANOVA and Regression } \\
\text { and Prediction Statistics }\end{array}$}} & \multicolumn{4}{|c|}{ Flame Condition and Disc Type } \\
\hline & & & FR_Pt & FL_Pt & FR_Pd & FL_Pd \\
\hline \multirow{3}{*}{\multicolumn{2}{|c|}{$\begin{array}{l}\text { Regression } \\
\text { Statistics }\end{array}$}} & $R^{2}$ & 0.9453 & 0.9812 & 0.9547 & 0.9588 \\
\hline & & Adjusted $R^{2}$ & 0.9446 & 0.9809 & 0.9536 & 0.9582 \\
\hline & & Standard Error & 1.526 & 0.9015 & 1.330 & 1.098 \\
\hline \multirow{6}{*}{ 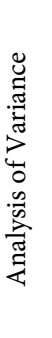 } & \multirow{2}{*}{ Regression } & MS & 2818.2 & 2867.6 & 1578.1 & 1872.8 \\
\hline & & $\mathrm{df}$ & 3 & 3 & 5 & 3 \\
\hline & \multirow{3}{*}{ Residual } & MS & 2.328 & 0.8126 & 1.768 & 1.206 \\
\hline & & $\mathrm{df}$ & 210 & 203 & 212 & 200 \\
\hline & & $F$ & 1210.7 & 3528.8 & 892.6 & 1552.6 \\
\hline & \multicolumn{2}{|c|}{ Significance $F$} & $3.20 \mathrm{E}-132$ & $8.23 \mathrm{E}-175$ & $3.07 \mathrm{E}-140$ & $3.19 \mathrm{E}-138$ \\
\hline \multirow{5}{*}{ 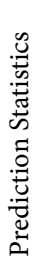 } & & RESS & 508.4 & 171.7 & 396.1 & 250.7 \\
\hline & & $R_{\text {pred }}^{2}$ & 0.9432 & 0.9804 & 0.9521 & 0.9572 \\
\hline & & leqval & 118.9 & 193.6 & 106.0 & 132.2 \\
\hline & & CV & 6.056 & 4.156 & 6.522 & 4.984 \\
\hline & Average Abs & lute Deviation \% & 12.31 & 7.799 & 12.91 & 8.884 \\
\hline
\end{tabular}

the small values of $(A A D)$ support the competence of the employed equations [10] [13] [18] [29] [37] [38]. These results indicate that the prediction of the temperature profile for any new data for the factors $x \& r$ within the investigated limits could be achieved employing the developed equation models.

The values of only the important coefficients of Equation (6) beside the corresponding low values of $\mathrm{p}<\alpha=0.05$, small Standard Error and large $t$-Stat are depicted in Table 3 . The very small coefficients limits in comparison with their corresponding ones which mean that they do not span the zero as a value for the parameter ensures the reliability of recognized equations for prediction for new data [18]. The empty cells belong to the excluded non-significant coefficients. The positive sign in front of the model terms indicates synergistic effect while the negative sign indicates antagonistic effect of the independent variables [39].

The quadratic terms in Equation (6) indicate the occurrence of curvatures. The negative signs for $R^{2} \& X^{2}$ reveal that the quadratic curves are concave. This means that the temperature increases with an increase in $X$ up to a maximum value beyond which the temperature decreases with further increase of the distance above the disk [21]. The temperature always decreases with the increase of radial distance from the center line of the flame. This is more pronounced for the case of FL Pt as it has the largest value of $\left|\beta_{1}^{2}\right|$ and $\mid t$-stat l and the smallest $\mathrm{p}$-value. The magnitude of the coefficients of the quadratic terms indicates the steepness of the curvature (Figures 7(a)-(d)) FL_Pt > FR_Pt $>$ FR_Pd $>$ FL_Pd [21]. 
Table 3. Estimated Regression Parameters for the Catalytic Flame Stabilizing Disc Burners. $Y=\beta_{0}+\beta_{1} * R+\beta_{2} * X+\beta_{1}^{2} * R^{2}+\beta_{2}^{2} * X^{2}+\beta_{12} * R * X$.

\begin{tabular}{|c|c|c|c|c|c|}
\hline & \multirow{2}{*}{ Regression Parameters } & \multicolumn{4}{|c|}{ Flame Condition and Disc Type } \\
\hline & & FR_Pt & FL_Pt & FR_Pd & FL_Pd \\
\hline & Coeff. & 34.29 & 29.80 & 28.04 & 29.47 \\
\hline & \pm C.L. & 0.3694 & 0.2216 & 0.3243 & 0.2734677 \\
\hline \multirow[t]{5}{*}{$\beta_{0}$} & Standard Error & 0.1874 & 0.1124 & 0.1645 & 0.1387 \\
\hline & $t$-Stat & 183.0 & 265.1 & 170.4 & 212.5 \\
\hline & p-value & $1.55 \mathrm{E}-233$ & $7.73 \mathrm{E}-260$ & $8.20 \mathrm{E}-229$ & $1.59 \mathrm{E}-237$ \\
\hline & Coeff. & & & 1.085 & \\
\hline & \pm C.L. & & & 0.3767 & \\
\hline \multirow[t]{5}{*}{$\beta_{1}$} & Standard Error & & & 0.1911 & \\
\hline & $t$ Stat & & & 5.678 & \\
\hline & p-value & & & $4.44 \mathrm{E}-08$ & \\
\hline & Coeff. & 3.999 & 5.176 & 6.106 & 4.153 \\
\hline & \pm C.L. & 0.3339 & 0.2146 & 0.2997 & 0.2429157 \\
\hline \multirow[t]{5}{*}{$\beta_{2}$} & Standard Error & 0.1694 & 0.1088 & 0.1520 & 0.1232 \\
\hline & $t$-Stat & 23.61 & 47.56 & 40.17 & 33.71 \\
\hline & p-value & $5.23 \mathrm{E}-61$ & $5.10 \mathrm{E}-112$ & $4.54 \mathrm{E}-101$ & $1.99 \mathrm{E}-84$ \\
\hline & Coeff. & -12.49 & -14.43 & -10.41 & -9.798 \\
\hline & \pm C.L. & 0.6268 & 0.3925 & 0.5677 & 0.4740326 \\
\hline \multirow[t]{5}{*}{$\beta_{1}^{2}$} & Standard Error & 0.3179 & 0.1991 & 0.2880 & 0.2404 \\
\hline & $t$ Stat & -39.30 & -72.48 & -36.14 & -40.76 \\
\hline & p-value & $9.41 \mathrm{E}-99$ & $4.65 \mathrm{E}-147$ & $1.41 \mathrm{E}-92$ & 7.97E-99 \\
\hline & Coeff. & -10.89 & -6.548 & -7.393 & -8.382 \\
\hline & \pm C.L. & 0.5699 & 0.3558 & 0.4957 & 0.4137794 \\
\hline \multirow[t]{5}{*}{$\beta_{2}^{2}$} & Standard Error & 0.2891 & 0.1804 & 0.2515 & 0.2098 \\
\hline & $t$-Stat & -37.68 & -36.29 & -29.40 & -39.94 \\
\hline & p-value & $2.12 \mathrm{E}-95$ & $1.07 \mathrm{E}-90$ & $9.79 \mathrm{E}-77$ & $2.87 \mathrm{E}-97$ \\
\hline & Coeff. & & & 1.018 & \\
\hline & \pm C.L. & & & 0.5907 & \\
\hline \multirow[t]{8}{*}{$\beta_{12}$} & Standard Error & & & 0.2997 & \\
\hline & $t$-Stat & & & 3.397 & \\
\hline & p-value & & & $8.15 \mathrm{E}-04$ & \\
\hline & Experimental Max. Temp. & 1275 & 1025 & 960 & 970 \\
\hline & Predicted Max. Temp. & 1200.8 & 949.9 & 861.8 & 898.9 \\
\hline & \% AD for Pred. Max. Temp. & 5.82 & 7.32 & 10.23 & 7.334 \\
\hline & $r$ for Max. Pred. Temp. & $1.93 \mathrm{E}-05$ & $1.13 \mathrm{E}-05$ & 5.44 & $2.53 \mathrm{E}-05$ \\
\hline & $x$ for Max. Pred. Temp. & 145.4 & 166.04 & 168.3 & 151.7 \\
\hline
\end{tabular}


The evidence for the validity of the regression models and their high capability to forecast the response has been affirmed in the high correlation between the experimental data and predicted values $\left(R^{2}>0.9\right)$ exposed in Figures $2(\mathrm{a})-(\mathrm{c})$ [29] [38]. The straight line of the normal probability plot of the studentized residuals in Figures 3(a)-(d) implies the normal distribution of errors [24]. The structureless pattern in the plots of the studentized residuals versus run number or predicted response (Figure 4 \& Figures 5(a)-(d)) indicate the satisfaction of the equation models and the absence of any violation of the independence or constant variance involved in the ANOVA assumptions [24] [33] [35].

\subsection{Equation Models in Terms of Natural Factors}

OLS method also has been utilized to explore the relation between the response variable and the natural independent variables. The following equations have been attained for the fuel rich (FR) and fuel lean (FL) cases:

For FR_Pt

$$
\operatorname{sqrt}(T)=10.428+0.3332 * x-2.221 \mathrm{E}-3 * r^{2}-1.146 \mathrm{E}-3 * x^{2}
$$

For FL_Pt

$$
\operatorname{sqrt}(T)=11.831+0.2287 * x-2.57 \mathrm{E}-3 * r^{2}-6.89 \mathrm{E}-4 * x^{2}
$$

For FR_Pd

$$
\begin{aligned}
\operatorname{sqrt}(T)= & 7.414-3.28 \mathrm{E}-3 * r+0.2609 * x-1.85 \mathrm{E}-3 * r^{2} \\
& -7.78 \mathrm{E}-4 * x^{2}+1.39 \mathrm{E}-4 * r * x
\end{aligned}
$$

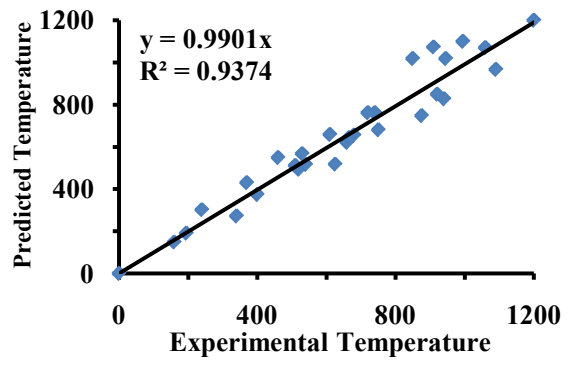

(a)

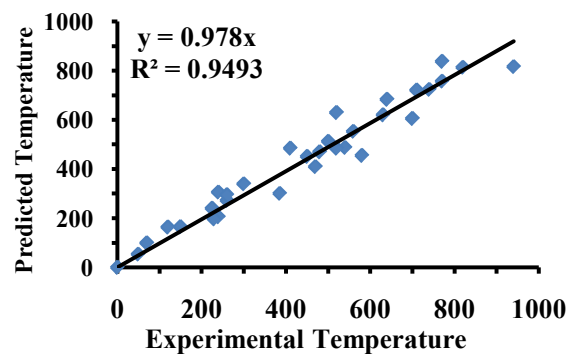

(c)

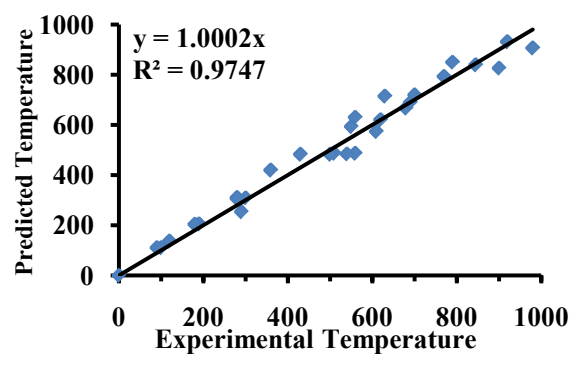

(b)

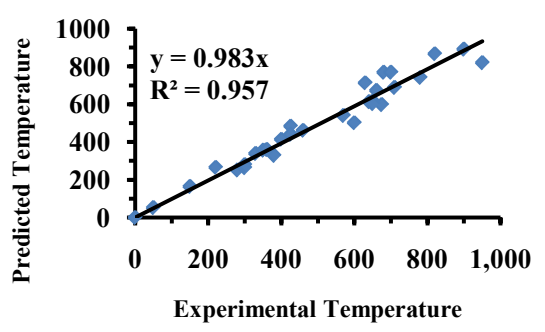

(d)

Figure 2. (a) Predicted Temp. vs Experimental Temp. for FR_Pt; (b) Predicted Temp. vs Experimental Temp. for FL_Pt; (c) Predicted Temp. vs Experimental Temp. for FR_Pd; (d) Predicted Temp. vs Experimental Temp. for FL_Pd. 


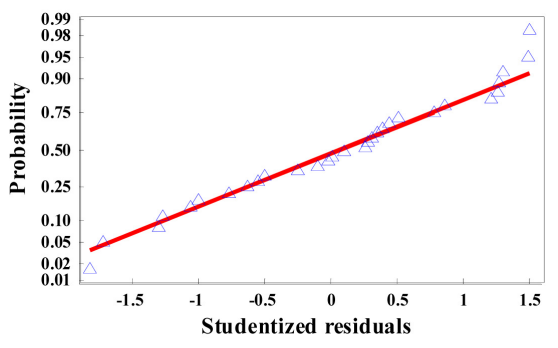

(a)

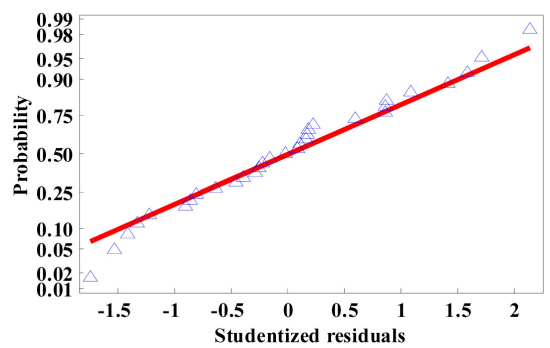

(c)

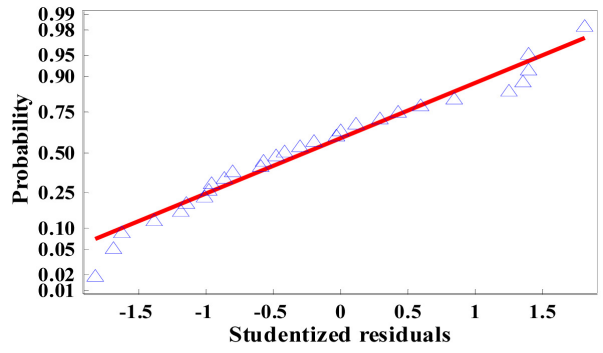

(b)

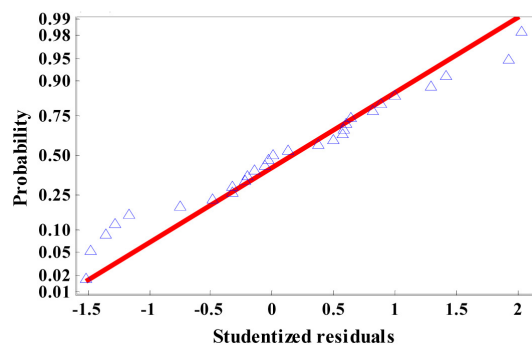

(d)

Figure 3. (a) A polt of Studentized residuals for FR-Pt; (b) Normal polt of Studentized residuals for FL-Pt; (b) Normal polt of Studentized residuals for FR-Pd; (b) Normal polt of Studentized residuals for FL-Pd.

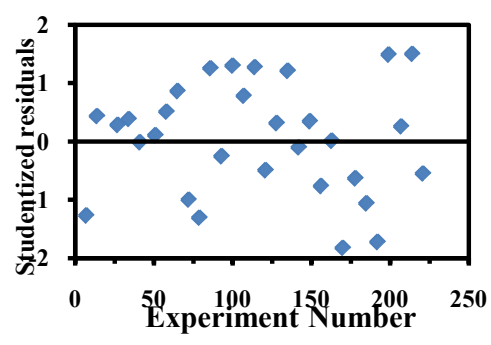

(a)

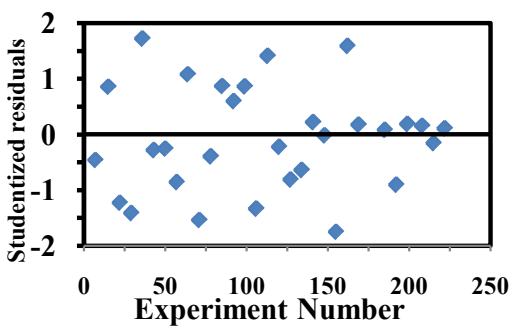

(c)

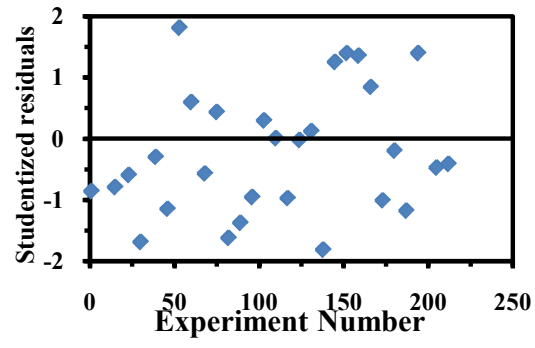

(b)

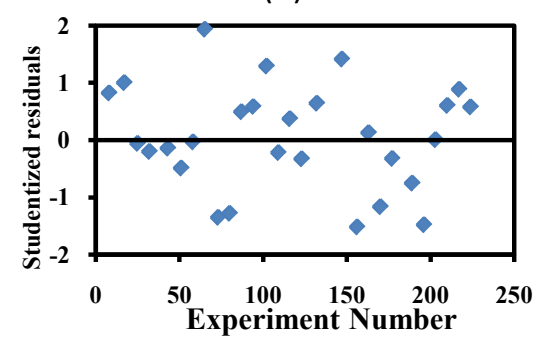

(d)

Figure 4. (a) Studentized residuals vs Experiment Number for FR_Pt; (b) Studentized residuals vs Experiment Number for FL_Pt; (c) Studentized residuals vs Experiment Number for FR_Pd; (d) Studentized residuals vs Experiment Number for FL_Pd.

\section{For FL_Pd}

$$
\operatorname{sqrt}(T)=9.703+0.2674 * x-1.74 \mathrm{E}-3 * r^{2}-8.82 \mathrm{E}-4 * x^{2}
$$

\subsection{Response Surface Plots}

Matlab 8.1 has been employed to perform the Response Surface plots for the 


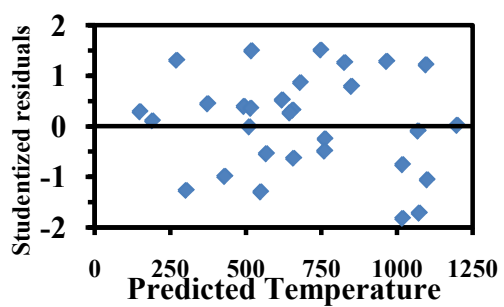

(a)

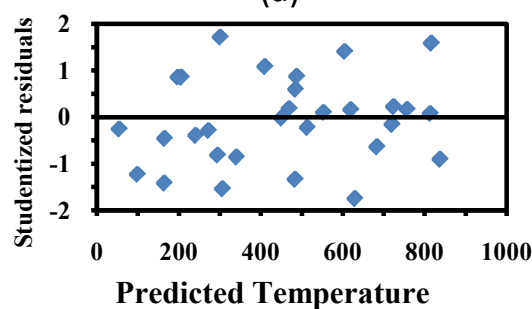

(c)

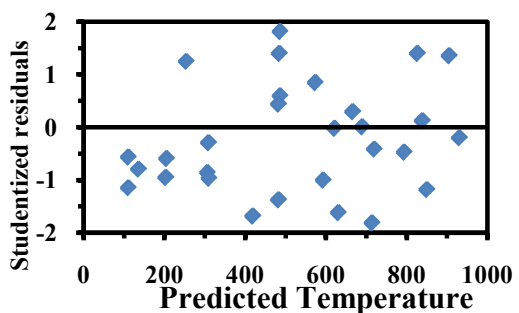

(b)

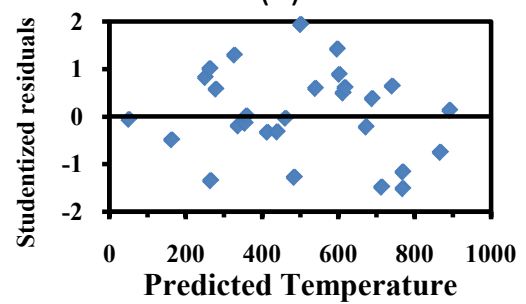

(d)

Figure 5. (a) Studentized residuals vs Predicted Temperature for FR_Pt; (b) Studentized residuals vs Predicted Temperature for FL_Pt; (c) Studentized residuals vs Predicted Temperature for FR_Pd; (d) Studentized residuals vs Predicted Temperature for FL_Pd.

predicted temperatures versus the actual natural variables of $(r)$ and $(x)$ for the above developed equation models (8)-(11) as exemplified in Figures 6(a)-(d) together with the corresponding experimental values. This graphical interpretation displays the interactions among the input variables and shows the best operating conditions of a process along with the maximum response [38]. Most of the experimental values fall on the predicted Response Surface which supports the accuracy of the developed model equations. The two dimensional contour plots have been exposed in Figures 7(a)-(d) along with the corresponding maximum predicted responses. The curvature natures of these plots indicate the interaction of their independent variables [38].

\subsection{Optimization}

An optimization process has been performed for the above presented Equations (8)-(11) to estimate the maximum predicted temperature and the corresponding $r$ and $(x)$ values. This has been achieved with the aid of the provisional maximum values obtained from the RSM plots for initial guessing, and utilizing Matlab 8.1. The Matlab implements a multidimensional unconstrained nonlinear optimization employing the Nelder-Mead simplex (direct search) method.

Table 3 depicts the maximum predicted temperature together with the analogous maximum experimental one. The small values of the $\%$ absolute deviation $(\mathrm{AD}) \leq 10$ for the forecasted maximum temperature from the conforming maximum experimental values supports the capability of the employed predictive equations.

\section{Conclusion}

The response surface methodology (RSM) with the aid of Box-Cox method has 


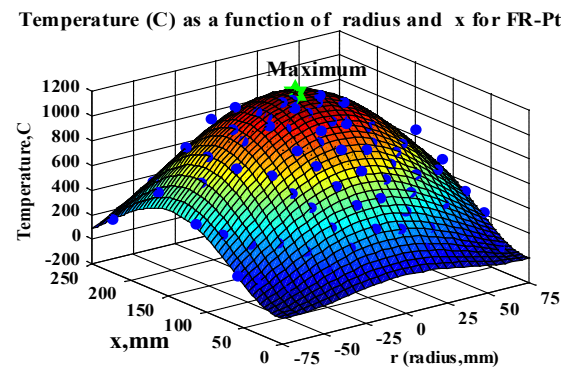

(a)

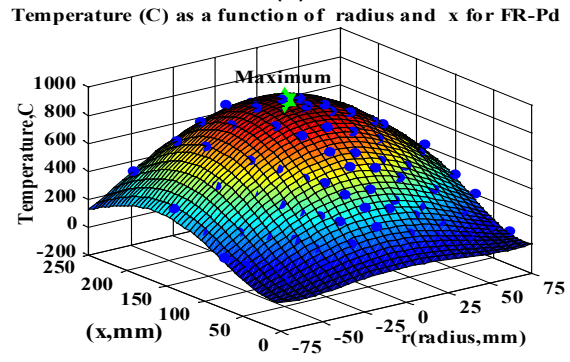

(c)

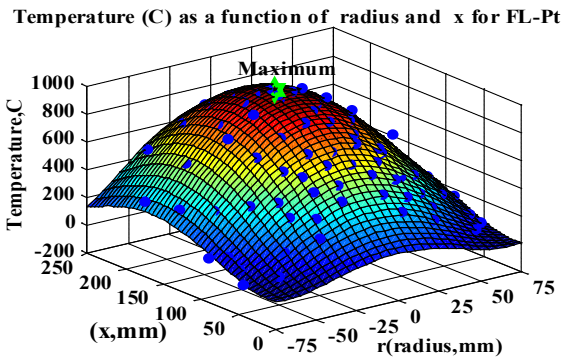

(b)

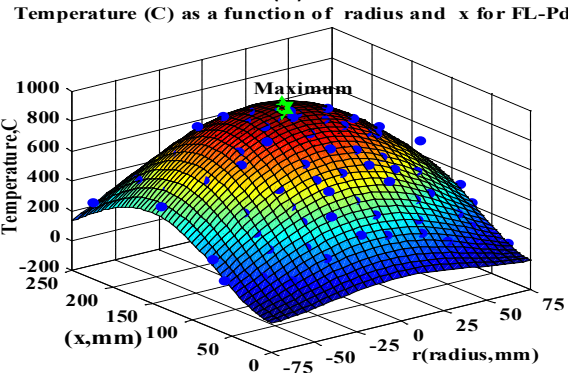

(d)

Figure 6. (a) Surface plot for FR_Pt; (b) Surface plot for FL_Pt; (c) Surface plot for FR_Pd; (d): Surface plot for FL_Pd.

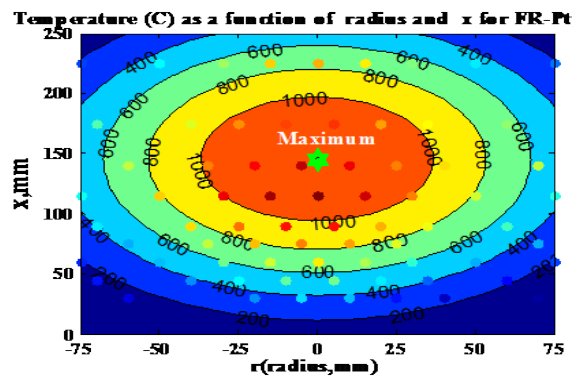

(a)

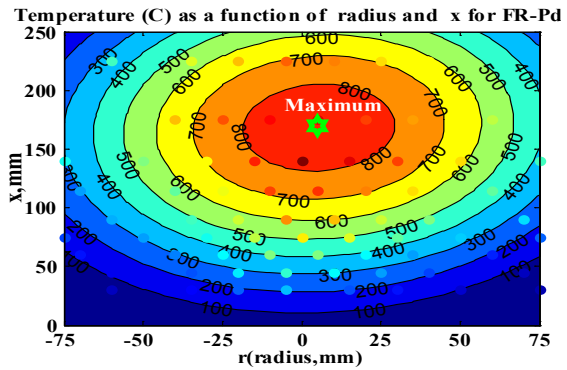

(c)

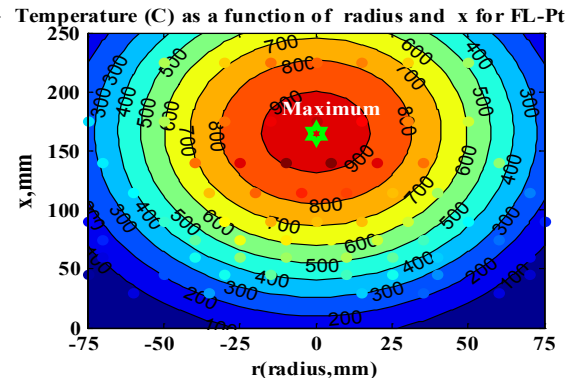

(b)

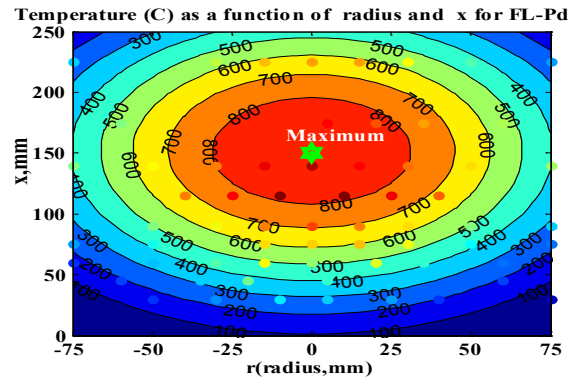

(d)

Figure 7. (a): Contour plot for FR_Pt; (b) Contour plot for FL_Pt; (c) Contour plot for FR_Pd; (d) Contour plot for FL_Pd.

been exploited to establish the suitable relations for the effect of radial distance from the center line of the flame $(r)$ and the axial distance above the disc $(x)$ on the thermal structure $(T)$ of the flames in the existence of the various catalytic stabilizing discs. The conventional least squares regression models showed outstanding prediction for the experimental results with high values for $R^{2}$ and 
$R_{\text {adj }}^{2}>0.95$, high values of calculated $F$-value; Adeqval, and small values of significance $F$ and $A A D$. Also good predictability for the response in a new experiment would be anticipated as revealed from the small values of PRESS and high values of $R_{\text {pred }}^{2}$. The response surface exemplified in the three dimensions depicted the response of the predicted variable $T$ to the variation of the considered variable parameters $r \& x$ with the good agreement between the experimental and predicted results and displayed the location of the predicted maximum temperature. The established equation models can be utilized for the estimation of the temperature profile for any new data for the factors $x \& r$ within the explored limits.

\section{Conflicts of Interest}

The authors declare no conflicts of interest regarding the publication of this paper.

\section{References}

[1] Arani, B.O., Frouzakis, C.E., Mantzaras, J. and Boulouchos, K. (2017) Three-Dimensional Direct Numerical Simulations of Turbulent Fuel-Lean $\mathrm{H}_{2} /$ Air Hetero-/Homogeneous Combustion over Pt with Detailed Chemistry. Proceedings of the Combustion Institute, 36, 4355-4363.

[2] Zheng, X., Mantzaras, J. and Bombach, R. (2013) Homogeneous Combustion of Fuel-Lean Syngas Mixtures over Platinum at Elevated Pressures and Preheats. Combustion and Flame, 160, 155-169.

https://doi.org/10.1016/j.combustflame.2012.09.001

[3] Schultze, M. and Mantzaras, J. (2013) Hetero-/homogeneous Combustion of Hydrogen/Air Mixtures over Platinum: Fuel-Lean versus Fuel-Rich Combustion Modes. International Journal of Hydrogen Energy, 38, 10654-10670. https://doi.org/10.1016/j.ijhydene.2013.06.069

[4] Smith, L.L., Karim, H., Castaldi, M.J., Etemad, S., Pfefferle, W.C., Khanna, V.K. and Smith, K.O. (2005) Rich-Catalytic Lean-Burn Combustion for Low-Single-Digit NOx Gas Turbine. Journal of Engineering for Gas Turbines and Power, 127, 27-35. https://doi.org/10.1115/1.1787510

[5] Schneider, A., Mantzaras, J. and Eriksson, S. (2008) Ignition and Extinction in Catalytic Partial Oxidation of Methane-Oxygen Mixtures with Large $\mathrm{H}_{2} \mathrm{O}$ and $\mathrm{CO}_{2}$ Dilution. Combustion Science and Technology, 180, 89-126. https://doi.org/10.1080/00102200701487087

[6] Lucci, F., Frouzakis, C.E. and Mantzaras, J. (2013) Three-Dimensional Direct Numerical Simulation of Turbulent Channel Flow Catalytic Combustion of Hydrogen over Platinum. Proceedings of the Combustion Institute, 34, 2295-2302.

[7] Schultze, M., Mantzaras, J., Bombach, R. and Boulouchos, K. (2013) An Experimental and Numerical Investigation of the Hetero-/Homogeneous Combustion of Fuel-Rich Hydrogen/Air Mixtures over Platinum. Proceedings of the Combustion Institute, 34, 2269-2277.

[8] Yan, Y., Wang, H., Pan, W., Zhang, L., Li, L., Yang, Z. and Lin, C. (2016) Numerical Study of Effect of Wall Parameters on Catalytic Combustion Characteristics of $\mathrm{CH}_{4} /$ Air in a Heat Recirculation Micro-Combustor. Energy Conversion and Management, 118, 474-484. https://doi.org/10.1016/j.enconman.2016.04.026 
[9] Zakhary, A.S., Aboul-Gheit, A.K. and Ghoneim, S.A. (2014) Fuel Rich and Fuel Lean Catalytic Combustion of the Stabilized Confined Turbulent Gaseous Diffusion Flames over Noble Metal Disc Burners. Egyptian Journal of Petroleum, 23, 79-86. https://doi.org/10.1016/j.ejpe.2014.02.011

[10] Braimah, M.N., Anozie, A.N. and Odejobi, O.J. (2016) Utilization of Response sUrface Methodology (RSM) in the Optimization of Crude Oil Refinery Process, New Port-Harcourt Refinery, Nigeria. Journal of Engineering Science and Technology, 3, 4361-4369.

[11] Khuri, A.I. (2017) A General Overview of Response Surface Methodology. Biometrics \& Biostatistics International Journal, 5, Article ID: 00133. https://doi.org/10.15406/bbij.2017.05.00133

[12] Khuri, A.I. (2017) Response Surface Methodology and Its Applications in Agricultural and Food Sciences. Biometrics \& Biostatistics International Journal, 5, Article ID: 00141. https://doi.org/10.15406/bbij.2017.05.00141

[13] Gendy, T.S., Zakhary, A.S. and El-Shiekh, T.M. (2017) Response Surface Methodology for Stabilized Turbulent Confined Jet Diffusion Flames Using Bluff-Body Burners. Journal of Scientific and Engineering Research, 4, 230-242.

[14] Bas, D. and Boyaci, I.H. (2007) Modeling and Optimization I: Usability of Response Surface Methodology. Journal of Food Engineering, 78, 836-845.

https://doi.org/10.1016/j.jfoodeng.2005.11.024

[15] Doust, A.M., Rahimi, M. and Feyzi, M.A. (2016) Optimization Study by Response Surface Methodology (RSM) on Viscosity Reduction of Residue Fuel Oil Exposed Ultrasonic Waves and Solvent Injection. Iranian Journal of Chemical Engineering, 13, 3-19.

[16] Gendy, T.S., El-Temtamy, S.A., Ghoneim, S.A., El-Salamony, R.A., El-Naggar, A.Y. and El-Morsi, A.K. (2016) Response Surface Methodology for Carbon Dioxide Reforming of Natural Gas. Energy Sources, Part A: Recovery, Utilization, and Environmental Effects, 38, 1236-1245. https://doi.org/10.1080/15567036.2013.876466

[17] Mesli, M. and Belkhouche, N.-E. (2018) Emulsion Ionic Liquid Membrane for Recovery Process of Lead. Comparative Study of Experimental and Response Surface Design. Chemical Engineering Research and Design, 129, 160-169. https://doi.org/10.1016/j.cherd.2017.11.011

[18] Moradi, G., Dabirian, F., Mohammadi, P., Rajabi, L., Babaei, M. and Shirib, N. (2018) Electrospun Fumarate Ferroxane/Polyacrylonitrile Nanocomposite Nanofibers Adsorbent for Lead Removal from Aqueous Solution: Characterization and Process Optimization by Response Surface Methodology. Chemical Engineering Research and Design, 129, 182-196. https://doi.org/10.1016/j.cherd.2017.09.022

[19] Mir, M.J. and Wani, M.F. (2018) Modelling and Analysis of Tool Wear and Surface Roughness in Hard Turning of AISI D2 Steel Using Response Surface Methodology. International Journal of Industrial Engineering Computations, 9, 63-74.

[20] Carley, M.K., Kamneva, N.Y. and Reminga, J. (2004) Response Surface Methodology. CASOS Technical Report, CMU-ISRI-04-136. http://www.casos.cs.cmu.edu

[21] Pambi, R.L.L. and Musonge, P. (2016) Application of Response Surface Methodology (RSM) in the Treatment of Final Effluent from the Sugar Industry Using Chitosan. WIT Transactions on Ecology and the Environment, 209, 209-219. https://doi.org/10.2495/WP160191

[22] Khajeh, M., Sarafraz-Yazdi, A. and Moghadam, A.F. (2017) Modeling of Solid-Phase Tea Waste Extraction for the Removal of Manganese and Cobalt from Water Samples by Using PSO-Artificial Neural Network and Response Surface Me- 
thodology. Arabian Journal of Chemistry, 10, S1663-S1673.

https://doi.org/10.1016/j.arabjc.2013.06.011

[23] Da Silva, G.F., Gandolfi, P.H.K., Almeida, R.N., Lucas, A.M., Cassel, E. and Vargas, R.M.F. (2015) Analysis of Supercritical Fluid Extraction of Lycopodine Using Response Surface Methodology and Process Mathematical Modeling. Chemical Engineering Research and Design, 100, 353-361. https://doi.org/10.1016/j.cherd.2015.05.039

[24] Malik, D. and Pakzad, L. (2018) Experimental Investigation on an Aerated Mixing Vessel through Electrical Resistance Tomography (ERT) and Response Surface Methodology (RSM). Chemical Engineering Research and Design, 129, 327-343. https://doi.org/10.1016/j.cherd.2017.11.002

[25] (2014) Engineering Statistics Handbook. http://www.itl.nist.gov/div898/handbook/index.htm

[26] Box, G.E.P., Hunter, W.G. and Hunter, J.S. (2005) Statistics for Experimenters: An Introduction to Design, Data Analysis, and Model Building. 2nd Edition, John Wiley \& Sons, New York.

[27] Weisberg, S. (2005) Applied Regression Analysis. 3rd Edition, John Wiley and Sons Inc., Hoboken.

[28] Hoffmann (2010) Linear Regression Analysis: Applications and Assumptions. 2nd Edition.

https://pdfs.semanticscholar.org/70e7/2c6f3aff895ac45643164e6839748a1e277d.pdf

[29] Yang, L., Yin, P., Fan, H., Xue, Q., Li, K., Li, X.,, Sun, L. and Liu, Y. (2017) Response Surface Methodology Optimization of Ultrasonic-Assisted Extraction of Acer Truncatum Leaves for Maximal Phenolic Yield and Antioxidant Activity. Molecules, 22, 232. https://doi.org/10.3390/molecules22020232

[30] Mei, D.H., Liu, S.Y. and Tu, X. (2017) $\mathrm{CO}_{2}$ Reforming with Methane for Syngas Production Using Dielectric Barrier Discharge Plasma Coupled with $\mathrm{Ni} / \gamma-\mathrm{Al}_{2} \mathrm{O}_{3}$ Catalysts: Process Optimization through Response Surface Methodology. Journal of $\mathrm{CO}_{2}$ Utilization, 21, 314-326.

[31] Adzamic, Z., Adzamic, T., Muzic, M. and Sertic-Bionda, K. (2013) Optimization of the n-Hexane Isomerization Process Using Response Surface Methodology. Chemical Engineering Research and Design, 91, 100-105. https://doi.org/10.1016/j.cherd.2012.06.012

[32] Setiabudi, H.D., Jalil, A.A., Triwahyono, S., Kamarudin, N.H.N. and Jusoh, R. (2013) Ir/Pt-HZSM5 for n-Pentane Isomerization: Effect of Si/Al Ratio and Reaction Optimization by Response Surface Methodology. Chemical Engineering Journal, 217, 300-309. https://doi.org/10.1016/j.cej.2012.12.011

[33] (2015) Experiment Design \& Analysis Reference. http://www.synthesisplatform.net/references/Experiment_Design_and_Analysis_Re ference.pdf

[34] Granato, D. and de Araujo Calado, V.M. (2014) The Use and Importance of Design of Experiments (DOE) in Process Modeling in Food Science and Technology. Mathematical and Statistical Methods in Food Science and Technology, John Wiley \& Sons, Ltd., Hoboken.

[35] Garlapati, V.K. and Roy, L. (2017) Utilization of Response Surface Methodology for Modeling and Optimization of Tablet Compression Process. Journal of Young Pharmacists, 9, 417-421.

[36] Larose, D.T. and Larose, C.D. (2015) Data Mining and Predictive Analytics. Wiley 
Series on Methods and Applications in Data Mining 2015.

[37] Javanbakht, V. and Ghoreishi, S.M. (2017) Application of Response Surface Methodology for Optimization of Lead Removal from an Aqueous Solution by a Novel Super Paramagnetic Nanocomposite. Adhesion Science and Technology, 35, 241-260. https://doi.org/10.1177/0263617416674474

[38] Azqhandi, M.H., Ghaedi, M., Yousefi, F. and Jamshidi, M. (2017) Application of Random Forest, Radial Basis Function Neural Networks and Central Composite Design for Modeling and/or Optimization of the Ultrasonic Assisted Adsorption of Brilliant Green on ZnS-NP-AC. Journal of Colloid and Interface Science, 505, 278-292. https://doi.org/10.1016/j.jcis.2017.05.098

[39] Kusworo, T.D., Ismai, A.F. and Mustafa, A. (2015) Experimental Design and Response Surface Modeling of pi/pes-zeolite 4a Mixed Matrix Membrane for $\mathrm{CO}_{2} \mathrm{Se}$ paration. Journal of Engineering Science and Technology, 10, 1116-1130. 